\title{
ELABORACION DE UNA TABLA DE DESARROLLO INFANTIL DE 0-36 MESES DE EDAD
}

\section{Planteamiento del problema}

El grupo de investigación preescolar, del Centro de Investigaciones de la Universidad Pedagógica Nacional, después de realizar una investigación sobre la situación de la educación preescolar pública en Bogotá, encontró que no existen programas destinados a favorecer el desarrollo psicomotor y social de los niños en la primera infancia. La atención se limita a los aspectos de alimentación, salud e higiene. Frente a esta realidad, el grupo se planteó la necesidad de elaborar un currículo para los niños de 0-3 años, destinado a fomentar el desarrollo psicomotor y social.

Un primer paso en la planeación curricular, fue la elaboración de una Tabla de Desarrollo con el fin de proporcionar un instrumento para evaluar el desarrollo infantil y determinar las conductas que debe presentar el niño en cada nivel de desarrollo y a partir de allí, realizar la planeación de actividades curriculares destinadas a desarrollar esas conductas.

\section{Objetivo}

El objetivo del presente estudio es la elaboración de un instrumento (Tabla de Desarrollo) que mida el desarrollo infantil y que permita ubicar al niño en períodos de desarrollo, a través de la determinación de las conductas esperadas para cada período.

La tabla debe tener las siguientes características:

-Ser muy sencilla, a fin de que personas no profesionales en el área como maestras de preescolar, enfermeras etc., puedan manejarla.

-Utilizar métodos de evaluación observables y confiables.

-Integrar autores que planteen diferentes enfoques y hagan énfasis, en las diferentes áreas del desarrollo.

\section{Metodología}

Al elaborar la Tabla de Desarrollo para el primer año de vida, se adelantaron las siguientes etapas:

\section{Etapa: Elaboración de las categorías de conducta}

Cada ítem de la Tabla, se denomina categoría de conducta e incluye una descripción clara del comportamiento esperado para determinado nivel y la actividad diseñada para observarlo.

Estas categorías fueron elaboradas después de hacer una revisión de autores en el área del desarrollo infantil temprano y de escalas de desarrollo ya existentes, con el fin de adaptar y elaborar las actividades para cada conducta estipulada por los autores. Se 
revisaron: Chauncey, Einstein, Gemelli, Gessel, Mussen, Piaget, Staats y Spitz entre otros.

2a. Etapa: Evaluación formativa de la tabla:

a) Aplicación evaluativa. Se realizaron dos aplicaciones de la Tabla de Desarrollo; cada una a 27 niños de sala cunas del Distrito, con el fin de evaluar las actividades diseñadas para observar la conducta y las definiciones de la misma.

b) Redefinición de las categorías. Con base en la experiencia de la aplicación, se redefinieron algunas categorías de conducta; se simplificó y se adecuó el lenguaje, con el fin de hacerlo más sencillo y comprensible; y se pulieron o reelaboraron las actividades cuando se encontraron deficiencias.

\section{Etapa: Secuenciación de las Categorías}

Finalmente, se aplicó la totalidad de la tabla a otra muestra de sala cunas del Distrito y del Instituto Colombiano de Bienestar Familiar, para observar a qué edad aparecen en forma regular los distintos comportamientos y si desaparecen en algún momento determinado. En esta forma se obtuvo una secuencia cronológica de la aparición de las conductas, en niños de sala cunas, provenientes de una extracción socioeconómica baja.

\section{Adelantos de la investigación}

Hasta el momento se encuentra elaborada y evaluada la Tabla para el primer año de vida del niño.

La Tabla está compuesta por categorías de conductas que definen el comportamiento esperado, describen una actividad con el fin de provocarlo, especifican los elementos necesarios para realizar la actividad y la forma de evaluar y si la conducta aparece o no. Está dividida para el primer año en las siguientes áreas de desarrollo: motora general, manipulación, social, verbal, visual, táctil, auditiva y de conductas complejas. Las conductas están secuenciadas según su orden de aparición dentro de cada área.

La Tabla se presenta en folletos, uno para cada área de desarrollo. Cada folleto incluye las categorías ordenadas según su aparición cronológica. Cada hoja del folleto incluye una categoría de conducta, la descripción de su actividad, y los recursos necesarios para realizar la actividad. Se anexa un Manual de Instrucciones que consta de las siguientes partes: Instrucciones para la aplicación de la Tabla de Desarrollo, Controles, Instrucciones para la evaluación de un niño, Lista de recursos de Trabajo y Descripción de Términos utilizados en la Tabla. Además, se anexa una guía, que presenta la ubicación cronológica de las categorías encontradas en la muestra de sala cunas, como orientación para evaluar niños de poblaciones semejantes.

\section{Proyecciones de la Tabla de Desarrollo:}

La Tabla será utilizada como uno de los instrumentos de evaluación para medir los efectos que sobre los niños tenga el currículo para madres y para profesionales, que diseña el grupo de investigación. La secuenciación cronológica de las categorías 
encontradas en niños de sala cunas presenta la posibilidad de que la Tabla sea utilizada para la evaluación de niños provenientes de ambientes similares.

Aún cuando la presente investigación no puede emprender un trabajo de estandarización, sería interesante la futura realización de este trabajo, el cual proporcionaría un instrumento de evaluación para la población infantil, diseñado y estandarizado para la población colombiana.

Para una información más detallada ver: Informe sobre la Realización y Prueba de una Tabla de Desarrollo del niño de 0-12 meses de edad. Centro de Investigaciones Universidad Pedagógica Nacional, Bogotá, 1970. 